\title{
An Environmental and Economic Performance Measure for Industrial Supply Networks
}

\author{
$\underline{\text { Samaneh Shokravi }}^{\text {a b }}$

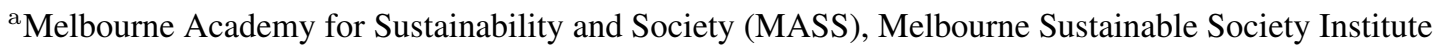 \\ (MSSI), The University of Melbourne, Parkville, VIC 3010, Australia \\ ${ }^{b}$ Department of Mechanical Engineering, The University of Melbourne, Parkville, VIC 3010, Australia \\ Email: s.shokravi@pgrad.unimelb.edu.au
}

\begin{abstract}
This paper aims at establishing a quantitative measure for economic and environmental Performance of industrial supply networks. To the best of the author's knowledge, this measure is the only one that considers aleatory and epistemic uncertainties in its environmental performance evaluation. The measure is built upon economic and environmental performance evaluation models. These models address identified shortcomings in the literature such as incomplete and inaccurate calculation of environmental impacts, as well as the disregard for aleatory and epistemic uncertainties in the input data. This measure provides an approach to quantify the environmental and economic performances, and accordingly the sustainability performance, of the supply network. Moreover, as this measure is not specified for an industrial sector, it can be employed for initializing a dialogue between members of supply networks about their sustainability performance. This can lead into an establishment of sustainability databases that are useful for both the network members and researchers. The measure does not account for the social component of sustainability. This is due to the lack of information about social aspects of organizations and hence their supply network. Moreover, as organizations have no strategies in place to collect information relevant to the supply chain, data for the demonstration of the method is not accessible to the researcher. Thus, the implementation of the model in a real world scenario is left for future studies upon the completion of data collections. The measure is based on ratio indicators that facilitate the comparison between current and future performances. This facilitates creating a set of sustainability targets necessary for establishing a sustainable management system within an organization. Moreover, the measure provides information to the process manager about the relationship between environmental safety decisions and the process's profit, when the process is a part of a supply network. Furthermore, this measure provides a common language for the companies to extend their individual sustainability targets toward the whole supply network.
\end{abstract}

Keywords: Conceptual Model, Dyadic, Environmental Performance, Industrial Sector, Profit, Reliability, Revenue sharing, Supply Chain Performance 


\section{INTRODUCTION}

Planning, controlling and designing a sustainable supply chain as a whole is of strategic importance for an organization (Soylu et al., 2006). Sustainability performance measures are used to evaluate the organization's success toward a sustainable supply chain. In the literature, it is rare to find such a measure that comprehensibly quantifies three pillars of sustainability - environmental, social and economic. For instance, some organizations are attempting to improve their environmental performance by employing customized indicators, however, they are not able to incorporate their supply chain as no inclusive method currently exists (Styles et al., 2012). Moreover, isolated attempts of organizations toward sustainability will not necessary translate into a sustainable supply chain.

As Seuring (2013) reported, more than 309 papers were published in the green or sustainable supply chain domain in the past 15 years. Of these, only 36 papers have applied quantitative methods to examine environmental or economic issues in the supply chain. Each paper only examines one specific aspect of the supply chain, such as energy consumption (Soylu et al., 2006), transportation (Dekker et al., 2012), single product supply (Georgiadis and Vlachos, 2004) or supply chain profit (Bai et al., 2012). Moreover, the examined environmental aspects in these methods merely include carbon dioxide emissions (green supply chain) and water/energy consumption (Kainuma and Tawara, 2006; Georgiadis and Vlachos, 2004). Several other environmental impacts exist that should be included in these methods, such as toxicity, substances' carcinogenic effects, resource depletion and chemical absorption (Shokravi et al., 2012). The consideration for the economic sustainability also can be extended to include various perspectives of a supply chain, such as revenue sharing and revenue competition, for the total cost and net revenues (Seuring, 2013).

Delai and Takahashi (2011, P. 438) found that "there is not a single initiative that tackles all sustainability issues and there is not a consensus as to what should be measured, or even how it is to be measured, mainly regarding to the social and economic aspects of sustainability.” Seuring and Muller (2008) and Hassini et al. (2012) also concluded that the few incomplete existing sustainability performance measures are based on the traditional definition of performance — time, cost and quality (Rusinko, 2007; Cox, 1999) - therefore they are incompatible with supply chain implementations, which consider performance according to planet, people and profit. Hence, the supply chain domain lacks a performance measure that considers all environmental and economic aspects of sustainability according to this new performance definition.

As reported by Bai and Sarkis (2010), there is no formal method for environmental performance evaluation of the broad supply chain. This shortcoming with the lack of a holistic environmental performance evaluation method (Shokravi et al., 2012), the lack of a suitable performance measure for the complete supply chain (Hieber, 2002; Gunasekaran and Kobu, 2007; Styles et al., 2012) and the necessity for a measure that considers cross industry studies (Akyuz and Erkan, 2010), reinforce the need for an inclusive sustainability performance measure. This paper tries to respond to this need, hence it presents a measure built upon economic and environmental performance evaluation models that can eventually lead to addressing the mentioned shortcomings.

\section{INDUSTRIAL SUPPLY NETWORK}

An industrial supply network is a combination of interconnected supply chains including industrial processes from various sectors that focus on supplier-manufacturer and manufacturer-manufacturer dyads (Miemczyk et al., 2012) (Figure 2). This definition might slightly differ across sectors or according to the members in the network (Lummus et al., 2001; van Hoek, 1998). This paper considers a simple approach toward defining a network and assumes a linear time invariant relation between the member of the network as presented in Figure 2. The proposed sustainability measure for industrial supply network is composed of two environmental and economic performance measures.

\section{ENVIRONMENTAL PERFORMANCE}

Environmental performance of an industrial process evaluates the relationship between the process and the environment, for instance it includes the environmental effects of resources consumed, the environmental impacts of the process, the environmental implications of its products, the recovery and processing of products

. Environmental Performance Evaluation (EPE) methods provide management with reliable information on whether the environmental performance of the organization is acceptable or not. This information is presented as indices that partially reveal the harmful effects of the process, and how to decrease these effects by altering the process's operation (Palaniappan, 2004). The majority of these indices are based on scoring and ranking 


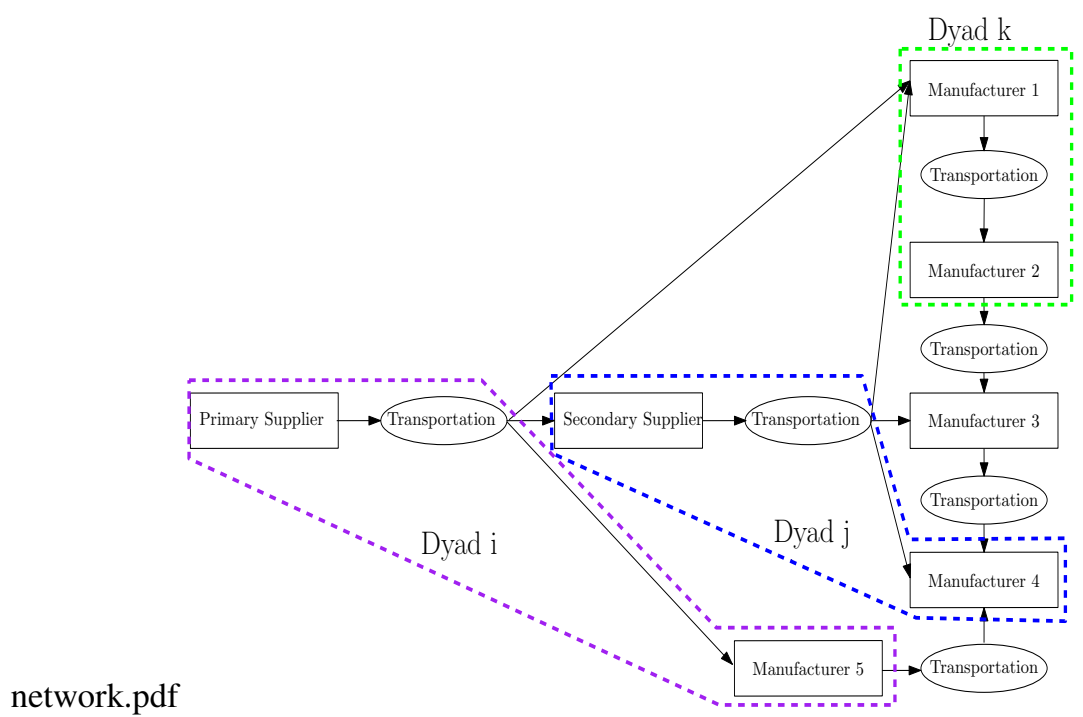

Figure 1. A Supply Network Example for the Proposed Measure- Supplier-Manufacturer and ManufacturerManufacturer dyads are shown as Dyad i,j and k.

approaches, which have limitations and uncertainties due to biased expert judgments (Jia et al., 2004).

Moreover, Environmental Performance Indices (EPI) lack inclusive hazard evaluations and uncertainty appraisal that lead to unreliable results. Ranking and scoring based EPIs are capable of comparison between processes based on their environmental hazard, but it is not clear how complete and rigorous these comparisons are. An EPE method proposed by Shokravi et al. (2012) provides an index called Environmental Performance Parameter $(E P P)$ that encapsulates the harmful impacts of an industrial process on the environment, and how operation and maintenance policies can decrease such impacts. EPP is readily comprehensible by non-experts and is not computationally intensive when compared to other EPIs. This index can be used to engage employees at all levels with associated environmental performance assessment programs and schemes.

$E P P$ is based on a Markov-like model that considers the transition probabilities to be dependent on time and the reliability of the system. It models the operational and non-operational states of the process capturing the aleatory uncertainty, which is the natural variability of the industrial operation. The environmental impacts in this model are summarized through an Impact Function $(I F u)$ and weights that capture the likelihood of an accident occurring at each state. The PIH models the uncertainty due to incomplete data collection, known as epistemic uncertainty. The impacts are calculated using the equations presented in Table 1 in (Shokravi et al., 2012) and the weights are the ratio between the standard level of chemical release to the environment according to the EPA guidelines ${ }^{1}$ and their actual occurrence. These ratios are the distance between ideal and current condition of the process. Since they use likelihood inputs, they capture the epistemic uncertainty or the lack of complete data collection.

The EPP value is calculated through Equation 1, by first initializing the process information and calculating the environmental impact for each subprocess. Then, the transition matrix and the state distribution vector are calculated. Finally the EPP for the whole process is calculated as Equation 1.

$$
E P P=\sum_{t=1}^{n}\left(\sum_{u=1}^{n_{u}}\left(\mu_{u}(t) \times I F u_{u}^{\top}\right)\right)
$$

in which $\times$ is a vector multiplication, $\mu_{u}$ is a vector of probabilities that show the subprocess is in operating or non-operating states. $n_{u}$ is the total number of these subprocess. $t$ is hour time step and $n$ is the total process time steps.

By defining the complete supply network as demonstrated in Figure 2 for the sake of simplicity, the suppliermanufacturer and manufacturer-manufacturer dyads are considered linear time invariant, which might not

\footnotetext{
${ }^{1}$ http://www.epa.vic.gov.au/business-and-industry/guidelines
} 
apply to the complex interactions among them but is seeding a view that has not been approached before. Hence, the Supply Network EPP (SNEPP) is the summation of the processes' EPPs and the EPPs for the transportation links as given by Equation 2. The transportation is considered separately in this model similar to economic performance measurement. This is due to the fact that the environmental impacts of the transportation are from specific categories of emissions and fuel consumption. By separating transportation in the calculation of EPP, the identification and inclusion of their impact become easier for the model users as they are readily identifiable. $E P P_{S N}$ is the $E P P$ for each member of the supply network and $E P P_{S N L}$ is the $E P P$ for the links or the transportation between members.

$$
S N E P P=\sum_{S N=1}^{n_{S N}} E P P_{S N}+\sum_{S N L=1}^{n_{S N}-1} E P P_{S N L}
$$

\section{ECONOMIC PERFORMANCE}

To validate process feasibility, an economic evaluation happens at the beginning of the design stage. This evaluation considers capital investment and manufacturing costs (Biegler et al., 1997). Capital investment includes all the expenses at the beginning of the plant, such as cost to build and start up the process. The capital investment is given by fixed and working capitals. Manufacturing cost includes all the expenses that are made on a continuous basis over the life of the plant.

In this work, the individual profit function of each member in the supply network (e.g., supplier and manufacturer) is shown in Equation 3.

$$
P R=\sum_{S S=1}^{N}\left[A_{u_{S S}} \times \text { price }-\sum_{u=1}^{n_{u}} A_{u_{S S}} \times \overline{\text { price }}-\sum_{u=1}^{n_{u}}\left(1-A_{u_{S S}}\right) \times\left(C_{\text {main }}+C_{\text {staff }}+C_{U u t i}\right)-\sum_{u=1}^{n_{u}} A_{u_{S S}} \times C_{\text {Outi }}\right]
$$

Manufacturing costs considered in this paper are:

- Raw material costs that are used in a regular basis; which are not replaceable during the production and are generally purchased in bulk (Biegler et al., 1997). This cost is considered as $\overline{\text { price }}$ in the proposed Equation 3 in this paper.

- Credits that involve utility, by-products and usable purge gases that are generated in a regular basis; This can be counted as the positive cost for the process greatly dependent on the type of by-product(s) or co-product(s) (Biegler et al., 1997). This cost is considered as price in the proposed Equation 3 in this paper.

- Direct costs include labor, supervision, payroll, utilities, maintenance and etc. (Perry, 2008). These costs are considered as $C_{m a i n}, C_{\text {staff }}, C_{O u t i}$ and $C_{U u t i}$ in Equation 3.

The capital costs and value of the scrap equipment are not considered and only manufacturing costs and the profit of selling the product have been taken into account. In order to model the supply network consisting of supplier-manufacturer or manufacturer-manufacturer dyads, it is assumed that the relationship between them is the one of revenue-sharing and does not consider competition. Cachon and Lariviere (2005) proved that other contracts or relationships are special cases of revenue-sharing, hence, revenue-sharing is more general and used in this model. For instance, profit of a manufacturer and supplier in a revenue sharing relation is as shown in Equations 4-6 (Cachon and Lariviere, 2005).

$$
\begin{aligned}
& \pi_{m}=\phi R(\text { quan,price })-\left(c_{m}+w_{s}-\phi v\right) \times \text { quan } \\
& \pi_{s}=(1-\phi) R(\text { quan,price })-\left(c_{s}-w_{s}-(1-\phi) v\right) \times \text { quan } \\
& \pi_{S N}=\pi_{m}+\pi_{s}=R(\text { quan,price })-(c-v) \times \text { quan }
\end{aligned}
$$

where $c=c_{m}+c_{s}$. Supply Network Profitability $(S N P R)$ is given by Equation 7 .

$$
S N P R=\sum_{S N=1}^{n_{S N}} P R_{S N}+\sum_{S N L=1}^{n_{S N}-1} P R_{S N L}+\pi_{S N}
$$


$P R_{S N}$ is the $P R$ for each member of the supply network and $P R_{S N L}$ is the $P R$ for the links or the transportation between members. The transportation is measured separately in this model. As much as the transportation is part of the supply network, it has a different nature than a given industrial process. Hence, transportation is considered as a separate entity to incorporate this difference, especially when evaluating the environmental impacts of the supply network members.

\section{THE PROPOSED ECONOMIC ENVIRONMENTAL SUSTAINABILITY MEASURE}

The proposed Economic Environmental Sustainability Measure (EESM) considers environmental and economic performance for a supply network. The economic performance focuses on the profit of the supply network, calculating it through the model proposed in Section 4, while, the environmental performance is measured through the model presented in Section 3. This environmental performance calculates the level of adverse impacts that a supply network and its processes have on the environment. The future targets of the organizations are considered when calculating this environmental performance to include the include the organizations environmental management system and the relevant plans for future improvements.

The Economic Environmental Sustainability Measure (EESM), given by Equation 8, demonstrates the environmental harm from the supply network that can be improved by every dollar profit produced. Considering the variables involved in two performance measures, EESM is a useful tool for measuring and managing the sustainability as it identifies the environmental impacts, their importance, their source and the target to achieve if the organization is planning on continual improvement of its performance. It also identifies the resources that the organization and in general the supply network will require for amelioration. Logarithmic calculation for EESM confines the range of numbers and when organization is trying various avenues for EESM improvement even small differences between current and future values are detectable by employees and management.

$$
E E S M=\log _{10}\left(\frac{|S N P R|}{|S N E P P|}\right)=\log _{10}(|S N P R|)-\log _{10}(|S N E P P|)
$$

Equation 8 can results in a positive, negative or a zero value for EESM. In any case there are generic interpretation that can be done but a detailed analysis requires knowledge about the values of two environmental and economic performances. If EESM and PR are positive values, the supply network is environmentally and economically sustainable, i.e. $S N P R>S N E P P>0$. /This means that the network is economically viable and environmentally friendly or the network has the financial power to improve its own environmental performance. On the other hand, if both performances are positive but environmental performance is higher than economic performance, i.e. $0<P R<E P P$, EESM is a negative value and the supply network is not Economically Environmentally sustainable. If in any case, the profit value is negative, the supply network is not economically sustainable. For a case with equal environmental and economic performances, the values of these performances clarify the sustainability of the network.

\section{DISCUSSION AND CONCLUDING REMARKS}

In this work, the Sustainability Measure ( $E E S M$ ) for supply networks is presented. This unbiased and quantitative measure integrates the economic and environmental aspects of sustainability, and demonstrates the amount of harm that the supply network can cause to the environment and society for every dollar of profit that it produces. The environmental measure is based on ratio indicators that facilitate the comparison between current and future performances. It considers the uncertainty of input data due to the incomplete data collection and natural variability of the process. The economic measure considers the profit function, which is the most important aspect of the supply network as a business entity. It calculates the profit of the process, both as an individual and a member of its associated supply network.

Since sustainability measures are used mainly in management decision making procedures, it is important to be able to rely on the employed measure and be aware of its shortcomings and limitations. LCA as one of the dominant tools employed in decision making cannot take into account the existing uncertainty associated with the data or the system under analysis. Even LCA-based measures that are proposed for sustainability performance evaluation have high data intensity and are subjective to environmental perspective of the analysis instead of having a comprehensive approach towards economic and environmental pillars of sustainability.

The isolated attempts of single companies towards sustainability have heightened the interest of the society towards this issue, but no substantial progress has been made so far. A common language for all members of the network is required in order to convert these individual attempts into an inclusive and combined movement. 
Therefore, a common measure should be employed across sectors and networks to initiate this language. EESM could be a common ground for dialogue between companies and networks as it is not designed for a specific industrial sector or process.

The generality of EESM allows implementation in industrial processes from various industry sectors. The comparison between the EESM of these processes can initiate a network of information. The importance of information sharing in the supply chain domain is also mentioned in (Li et al., 2005). Seuring (2008) concluded that the problems with data collection in supply chain domain reveal the necessity for a more and better documentation and case studies. This paper is the first step for establishment of such an information network that assists the organizations to clarify their sustainability goals and management in alignment with their supply network members. It also assist the researchers with available and a more reliable set of data for further studies.

\section{APPENDIX A- NomenClature}

\begin{tabular}{|c|c|c|c|}
\hline$A_{u_{S S}}$ & Availability of the system & $c_{m}$ & The manufacturer's cost per unit \\
\hline$c_{s}$ & The supplier's cost per unit & $C_{\text {main }}$ & Cost of maintenance (cost per unit) \\
\hline$C_{\text {Outi }}$ & Cost of utility while in operation (cost per unit) & $C_{\text {staff }}$ & Cost of staff (cost per unit) \\
\hline$C_{U u t i}$ & Cost of utility while out of operation (cost per unit) & $E P P$ & Environmental Performance Parameter \\
\hline$E P P_{S N}$ & EPP for each member of the supply network & $n_{S N}$ & Number of supply network members \\
\hline$E P P_{S N L}$ & EPP for the supply network links & $I F u$ & Impact Function \\
\hline$n$ & Total process time & $N$ & Total number of system states \\
\hline$n_{u}$ & Total number of subprocesses & $n_{S N}$ & Total number of members in a supply network \\
\hline$P R$ & Individual profit function for a process & $P R_{S N}$ & Profit function for each process \\
\hline$P R_{S N L}$ & Profit function for the transportation links & price & value of the product manufactured by a process \\
\hline$\overline{\text { price }}$ & Raw material price & $R($ quan,price $)$ & The retailer's revenue for a quantity and price \\
\hline$E E S M$ & Sustainability Measure of the supply network & $S N$ & Number of members in a supply network \\
\hline$S N E P P$ & Supply Network EPP & $S N P R$ & Supply Network PR \\
\hline$S S$ & System State & $t$ & Time \\
\hline$u$ & Number of subprocesses & $v$ & The salvage price of the asset \\
\hline$w_{s}$ & The wholesale price that manufacturer pays & $\mu(t)$ & State probability distribution vector at time $t$ \\
\hline$\pi_{s}$ & The supplier's profit function & $\pi_{m}$ & The manufacturer's profit function \\
\hline$\phi$ & The revenue generated by the manufacturer & $\phi_{S N}$ & The supply network generated revenue \\
\hline
\end{tabular}

$$
\frac{1}{\sqrt{2}} B_{x-\delta x, y-\delta y}(t)+\frac{1}{\sqrt{2}} B_{x+\delta x, y+\delta y}(t)+\frac{1}{\sqrt{2}} B_{x-\delta x, y+\delta y}(t)+\frac{1}{\sqrt{2}} B_{x+\delta x, y-\delta y}(t)
$$

\section{REFERENCES}

Akyuz, G. A. and T. Erkan (2010). Supply chain peraformance measurement: a literature review. International Journal of Production Research 48, 5137-5155.

Bai, C. and J. Sarkis (2010). Green supplier development: analytical evaluation using rough set theory. Journal of Cleaner Production 18, 1200-1210.

Bai, C., J. Sarkis, X. Wei, and L. Koh (2012). Evaluating ecological sustainable performance measures for supply chain management. Supply Chain Management: An International Journal 17, 78-92.

Biegler, L., I. Grossmann, and A. Westerberg (1997). Systematic methods of chemical process design. Upper Saddle River, N.J. : Prentice Hall PTR.

Cachon, G. P. and M. A. Lariviere (2005). Supply chain coordination with revenue-sharing constracts: strenght and limitations. Management Science 51, 30-44.

Cox, A. (1999). Power, value and supply chain management. Supply Chain Management: An International Journal 4, 167-175. 
S. Shokravi, An Environmental and Economic Performance Measure for Industrial ...

Dekker, R., J. Bloemhof, and I. Mallidis (2012). Operations research for green logistics- an overview of aspects, issues, contributions and challenges. European Journal of Operation Research 219, 671-679.

Delai, I. and S. Takahashi (2011). Sustainability measurement system: a reference model proposal. Social Responsibility Journal 7, 438-471.

Georgiadis, P. and D. Vlachos (2004). The effect of environmental parameters on product recovery. European Journal of Operation Research 157, 449-464.

Gunasekaran, A. and B. Kobu (2007). Performance measures and metrics in logistics and supply chain management: a review of recent literature (1995-2004) for research and applications. International Journal of Production Research 45, 2819-2840.

Hassini, E., C. Surti, and C. Searcy (2012). A literature review and a case study of sustainable supply chains with a focus on metrics. International Journal of Production Economics 140, 69-82.

Hieber, R. (2002). Supply chain management: a collaborative performance measurement approach. vdf Hochschulverlag AG an der ETH Zrich.

Jia, X. P., F. Han, and X. Tan (2004). Integrated environmental performance assessment of chemical process. Computers \& Chemical Engineering 29, 5.

Kainuma, Y. and N. Tawara (2006). A multiple attribute utility theory approach to lean and green supply chain management. Journal of Production Economics 101, 99-108.

Li, G., H. Yan, S. Wang, and Y. Xia (2005). Comparative analysis on value of information sharing in supply chains. Supply Chain Management: An International Journal 10, 34-46.

Lummus, R. R., D. W. Krumwiede, and R. J. Vokurka (2001). The relationship of logistics to supply chain management: developing a common industry definition. Industrial Management and Data Systems 101, 426-432.

Miemczyk, J., T. E. Johnsen, and M. Macquet (2012). Sustainable purchasing and supply management: a structured literature review of definitions and measures at the dyad, chain and network levels. Supply Chain Management: An International Journal 17, 478-496.

Palaniappan, C. (2004). Selection of inherently safer process routes: a case study. Chemical Engineering and Processing: Process Intensification 43, 641-647.

Perry, R. (2008). Perry's chemical engineers' handbook. New York : McGrow-Hill.

Rusinko, C. A. (2007). Green manufacturing: an evaluation of environmentally sustainabile manufacturing practices and their impact on competitive outcomes. IEEE Transaction on Engineering Management 54, $445-454$.

Seuring, S. (2008). Assessing the rigor of case study research in supply chain management. Supply Chain Management: An International Journal 13, 128-137.

Seuring, S. (2013). A review of modeling approaches for sustainable supply chain management. Decision Support Systems 54, 1513-1520.

Seuring, S. and M. Muller (2008). From a literature review to a conceptual framework for sustainable supply chain management. Journal of Cleaner Production 16, 1699-1710.

Shokravi, S., A. J. R. Smith, C. R. Burvill, and S. Maheswararajah (2012, July 1-5). Industrial Environmental Performance Evaluation - Comparison and Sensitivity Analysis. In R. Seppelt, A. A. Voinov, S. Lange, and D. Bankamp (Eds.), International Environmental Modelling and Software Society (iEMSs) 2012 International Congress on Environmental Modelling and Software. Managing Resources of a Limited Planet: Pathways and Visions under Uncertainty, Sixth Biennial Meeting, pp. 1037-1044.

Soylu, A., C. Oruc, M. Turkay, K. Fujita, and T. Asakura (2006). Synergy analysis of collaborative supply chain management in energy systems using multi-period MILP. European Journal of Operation Research 174, 387-403.

Styles, D., H. Schoenberger, and J.-L. Galvez-Martos (2012). Environmental improvement of product supply chains: A review of European retailers' performance. Resource Conservation and Recycling 65, 57-78.

van Hoek, R. I. (1998). "measuring the unmeasurable" -measuring and improving performance in the supply chain. Supply Chain Management: An International Journal 3, 187-192. 